\title{
Pesticides in Agricultural Products: Analysis, Reduction, Prevention
}

\author{
Mohammad Shokrzadeh and Seyed Soheil Saeedi Saravi \\ Depatment of Toxicology-Pharmacology, Faculty of Pharmacy, \\ Mazandaran University of Mediccal Sciences, Sari
}

Iran

\section{Introduction}

Food is the basic necessity of life and food contaminated with toxic pesticides is associated with severe effects on the human health. Hence it is pertinent to explore strategies that address this situation of food safety especially for the developing countries where pesticide contamination is widespread due to indiscriminate usage and a major part of population lives below poverty line (Kaushik et al., 2009).

It is therefore of significance to evaluate simple, cost effective strategies to enhance food safety from harmful pesticides for poor populace.

As $\mathrm{FAO}^{1}$ defined, pesticide is any substance or mixture of substances intended for preventing, destroying, repelling or mitigating any pest, including vectors of human or animal disease, unwanted species of plants or animals causing harm during or otherwise interfering with the production, processing, storage, transport or marketing of food, agricultural commodities, wood and wood products or animal feedstuffs, or substances which may be administered to animals for the control of insects, arachnids or other pests in or on their bodies. The term includes substances intended for use as a plant growth regulator, defoliant, desiccant or agent for thinning fruit or preventing the premature fall of fruit, and substances applied to crops either before or after harvest to protect the commodity from deterioration during storage and transport (Food and Agriculture Organization of the United Nations, 2002). A pesticide may be a chemical substance, biological agent (such as a virus or bacterium), antimicrobial, disinfectant or device used against any pest. Pests include insects, plant pathogens, weeds, molluscs, birds, mammals, fish, nematodes (roundworms), and microbes that destroy property, spread disease or are a vector for disease or cause a nuisance. Although there are benefits to the use of pesticides, there are also drawbacks, such as potential toxicity to humans and other animals.

Pesticides can be classified by target organism, chemical structure, and physical state. Pesticides can also be classed as inorganic, synthetic, or biologicals (biopesticides) (Council on Scientific Affairs, American Medical Association, 1997), although the distinction can sometimes blur. Biopesticides include microbial pesticides and biochemical pesticides (EPA,

1 Food and Drug Administration 
2009). Plant-derived pesticides, or 'botanicals', have been developing quickly. These include the pyrethroids, rotenoids, nicotinoids, and a fourth group that includes strychnine and scilliroside (Kamrin, 1997). Many pesticides can be grouped into chemical families. Prominent insecticide families include organochlorines, organophosphates, and carbamates. Organochlorine hydrocarbons (e.g. DDT) could be separated into dichlorodiphenylethanes, cyclodiene compounds, and other related compounds. In addition, Pesticides can be classified based upon their biological mechanism function or application method.

Agricultural production has been accompanied by continuous growth in the number and quantity of agrochemicals applied to crops. Pesticide use is associated with environmental contamination and human health problems worldwide. Pesticides (insecticides, fungicides, etc.) are used globally for the protection of food, fibber, human health and comfort (Winteringham, 1971). Currently, more than 800 pesticide active ingredients in a wide range of commercial products are registered for use in agriculture to meet food supply demands. Pesticides are essential in modern agricultural practices but, due to their biocide activity and potential risk to the consumer, the control of pesticide residues in foods is a growing source of concern for the general population and environment. Over $98 \%$ of sprayed insecticides and $95 \%$ of herbicides reach a destination other than their target species, including non-target species, air, water and soil (Miller, 2004). Pesticide drift occurs when pesticides suspended in the air as particles are carried by wind to other areas, potentially contaminating them. Pesticides are one of the causes of water pollution, and some pesticides are persistent organic pollutants and contribute to soil contamination.

In addition, pesticide use reduces biodiversity, reduces nitrogen fixation, contributes to pollinator decline, destroys habitat (especially for birds), and threatens endangered species. It also happens that some of the pest adapt to the pesticide and don't die. What is called pesticide resistance, to eliminate the offspring of this pest, will be needed an new pesticide or an increase the dose of pesticide. This will cause a worsening of the ambient pollution problem (Rockets, 2007; Hackenberg, 2007; Wells, 2007; Haefeker, 2000; Zeissloff, 2001; Palmer et al., 2007; Winteringham, 1971).

Pesticides can be dangerous to consumers, workers and close bystanders during manufacture, transport, or during and after use (U.S. Environmental Protection Agency, 2007). Particular uncertainty exists regarding the long-term effects of low-dose pesticide exposures. Current surveillance systems are inadequate to characterize potential exposure problems related to pesticide usage or pesticide-related illnesses. The $\mathrm{WHO}^{2}$ and the $\mathrm{UN}^{3}$ Environment Program estimate that each year, 3 million workers in agriculture in the developing world experience severe poisoning from pesticides, about 18,000 of whom die (Winteringham, 1971). According to one study, as many as 25 million workers in developing countries may suffer mild pesticide poisoning yearly. There have been many studies of farmers intended to determine health effects of occupational pesticide exposure. Associations between non-Hodgkin lymphoma, leukemia, prostate cancer, multiple myeloma, and soft tissues sarcoma have been reported in studies, with less association found for other cancers (Jeyaratnam, 1990; McCauley, 2006).

\footnotetext{
${ }^{2}$ World Health Organization

${ }^{3}$ United Nation
} 
We are exposed to pesticides in the food and water we consume and in the air we breathe. The three main entry routes for pesticides into the body are dermal, (exposure through the skin or eyes), respiratory (inhalation into the lungs), and oral (ingestion by mouth). The amounts of pesticides that remain as residues in food are miniscule-sometimes only 1 millionth of a kilogramme. Thus, contact with the concentrated product during mixing and loading presents the greatest risk for exposure. The level of absorption depends on the properties of the pesticide, its formulation, and parts of the body exposed. Following exposure, human health risks from pesticides and herbicides may be caused by acute (short term) or chronic (long term) exposures (Rell \& Galvin, 2008).

However, the chapter tries to analysis of pesticide residues in agricultural products, determination of effective methods to reduce the residues, and prevention of food contamination, as vital works for worldwide health safety.

\section{Analysis}

In order to be able to set a maximum level, not only do the health risks have to be assessed but the residues must also be determinable analytically. Reliable residue analytical methods are necessary to measure the magnitude of residue in a commodity, and to enforce legal residue limits (tolerances). The Suitable analytical methods for the detection of pesticide residues in agricultural products includes the below stages:

\subsection{Sampling, transport, processing and storage of samples \\ 2.1.1 Sampling}

Laboratory samples should be taken in uncontaminated status and collected in nonabsorbable and non-leakage containers. Where it is impractical to take primary samples randomly within a lot, the method of sampling must be recorded.

\subsubsection{Laboratory sample transportation}

Samples must be transported under appropriate conditions to the laboratory in clean containers and robust packaging. Polythene bags, ventilated if appropriate, are acceptable for most samples but low permeability bags (e.g. nylon film) must be used for samples to be analyzed for residues of fumigants. Samples of commodities pre-packed for retail sale should not be removed from their packaging before transport. Very fragile or perishable products (e.g. ripe raspberries) may have to be frozen to avoid spoilage and then transported in 'dry ice' or similar, to avoid thawing in transit. Samples that are frozen at the time of collection must be transported without thawing. Samples that may be damaged by chilling (e.g. bananas) must be protected from both high and low temperatures.

Rapid transportation to the laboratory, preferably within one day, is essential for samples of most fresh products. The condition of samples delivered to the laboratory should approximate to that acceptable to a discerning purchaser, otherwise samples should normally be considered unfit for analysis.

Samples must be identified clearly, in a way that prevents inadvertent loss or confusion of labelling. The use of marker pens containing organic solvents should be avoided for labelling bags containing samples to be analyzed for fumigant residues, especially if an electron capture detector is to be used (Pihlström et al., 2009). 


\subsubsection{Sample preparation and processing prior to analysis}

Sample preparation, sample processing and sub-sampling to obtain analytical portions should take place before visible deterioration occurs. This is particularly important when the analytical result is to be used to assess consumer intake. Canned, dried or similarly processed samples should be analyzed within the stated shelf life.

Sample processing and storage procedures should be demonstrated to have no significant effect on the residues present in the analytical sample. Where there is evidence that comminuting (cutting and homogenization) at ambient temperature has a significant influence on the degradation of certain pesticide residues, it is recommended that samples are homogenized at low temperature (e.g. frozen and/or in the presence of 'dry ice'). Where comminuting is known to affect residues (e.g. dithiocarbamates or fumigants) and practical alternative procedures are not available, the test portion should consist of whole units of the commodity, or segments removed from large units. For all other analyses, the whole laboratory sample (in most cases $1-2 \mathrm{~kg}$ ) needs to be comminuted. All analyses should be undertaken within the shortest time practicable, to minimize sample storage. Analyses for residues of very labile or volatile pesticides should be started, and the procedures involved in potential loss of analyte completed, on the day of sample receipt. In any case, sample comminuting should ensure that the sample is homogeneous enough so that sub-sampling variability is acceptable. If this is not achievable, the use of larger test portions should be considered (Pihlström et al., 2009).

If a single analytical portion is unlikely to be representative of the analytical sample, replicate portions must be analyzed, to provide a better estimate of the true value.

\subsection{Pesticide standards and calibration solutions}

\subsubsection{Identity, purity, and storage of standards}

'Pure' standards of analytes should be of known purity and each must be uniquely identified and the date of receipt recorded. They should be stored at low temperature, preferably in a freezer, with light and moisture excluded, i.e. under conditions that minimize the rate of degradation. Under such conditions, the supplier's expiry date, which is often based on less stringent storage conditions, may be replaced, as appropriate for each standard, by a date allowing for storage up to 10 years. The pure standard may be retained if its purity is shown to remain acceptable. The purity should be checked by the allocated time after which a 'Pure' standard may be retained if its purity is shown to remain acceptable and a new expiry date is allocated. Ideally, the identity of freshly acquired 'Pure' standards should be checked if the analytes are new to the laboratory (Pihlström et al., 2009).

\subsubsection{Preparation and storage of stock standards}

When preparing stock standards (solutions, dispersions or gaseous dilutions) of 'Pure' standards of analytes and internal standards, the identity and mass (or volume, for highly volatile compounds) of the 'Pure' standard and the identity and amount of the solvent (or other diluents) must be recorded. The solvent(s) must be appropriate to the analyte (solubility, no reaction) and method of analysis. Moisture must be excluded during equilibration of the 'Pure' standard to room temperature before use and concentrations must be corrected for the purity of the 'Pure' standard. 
Not less than $10 \mathrm{mg}$ of the 'Pure' standard should be weighed using a 5 decimal place balance. The ambient temperature should be that at which the glassware is calibrated, otherwise preparation of the standard should be based on mass measurement. Volatile liquid analytes should be dispensed by weight or volume (if the density is known) directly into solvent. Gaseous (fumigant) analytes may be dispensed by bubbling into solvent and weighing the mass transferred, or by preparing gaseous dilutions (e.g. with a gas-tight syringe, avoiding contact with reactive metals).

Stock standards must be labelled indelibly, allocated an expiry date and stored at low temperature in the dark in containers that prevent any loss of solvent and entry of water. Currently available data show that stock standards of the large majority of pesticides in toluene and acetone are stable for at least 5 years in the freezer when stored in tightly closed glass containers.

For suspensions (e.g. dithiocarbamates) and solutions (or gaseous dilutions) of highly volatile fumigants that should be prepared freshly, the accuracy of the solution should be compared with a second solution made independently at the same time (Pihlström et al., 2009).

\subsubsection{Preparation, use and storage of working standards:}

When preparing working standards, a record must be kept of the identity and amount of all solutions and solvents employed. The solvent(s) must be appropriate to the analyte (solubility) and method of analysis. The standards must be labelled indelibly, allocated an expiry date and stored at low temperature in the dark in containers that prevent any loss of solvent and entry of water. Septum closures are particularly prone to evaporation losses (in addition to being a source of contamination) and should be replaced as soon as practicable after piercing, if solutions are to be retained. Following equilibration to room temperature, solutions must be re-mixed and a check made to ensure that no analyte remains nondissolved, especially where solubility at low temperatures is limited.

At method development or validation, or for analytes new to the laboratory, the response detected should be shown to be due to the analyte, rather than to an impurity or artefact. If the techniques used can lead to degradation of the analyte during extraction, clean-up or separation, and they generate a product that is commonly found in samples but which is excluded from the residue definition, positive results must be confirmed using techniques that avoid this problem (Pihlström et al., 2009).

\subsubsection{Testing and replacement of standards:}

Whenever any standard is used beyond its expiry date its stability should be verified. Existing stock and working solutions may be tested against newly prepared solutions by comparing the detector responses obtained from appropriate dilutions of individual standards or mixtures of standards. The purity of an old 'Pure' standard may be checked by preparing a new stock standard and comparing the detector responses obtained from freshly prepared dilutions of old and new stock standards. Inexplicable differences in apparent concentration between old and new standards must be investigated.

The means from at least three replicate measurements for each of two solutions (old and new) should not normally differ by more than $\pm 10 \%$. The mean from the new solution is taken to be $100 \%$. If the mean response of the old standard differs by more than $\pm 10 \%$ from 
the new, storage time or conditions must be adjusted as necessary on the basis of the results and should be checked against a second solution independently prepared from the first one. The use of an internal standard may reduce the number of replicate injections required to achieve a $\pm 10 \%$ difference (Pihlström et al., 2009).

\subsection{Extraction and concentration}

\subsubsection{Extraction conditions and efficiency}

Test portions should be disintegrated thoroughly during extraction to maximize extraction efficiency, except where this is known to be unnecessary or inappropriate (e.g. for determination of fumigants or surface residues). Temperature, $\mathrm{pH}$, etc., must be controlled if these parameters affect extraction efficiency, analyte stability or solvent volume. To improve the extraction efficiency of low moisture containing commodities (cereals, dried fruits), it is recommended to add water to the samples before extraction is carried out. However, the time between addition of water and extraction should be controlled in order to avoid any significant losses of pesticides. For instance in a method, a non-fatty test portion is blended with acetone and filtered; pesticides are transferred from aqueous filtrate to organic phase by shaking with petroleum ether and dichloromethane $\left(\mathrm{CH}_{2} \mathrm{Cl}_{2}\right)$. After drying, organic phase is concentrated in the presence of petroleum ether and then acetone to remove dichloromethane; an aliquot of concentrated organic phase is injected into various GC4 systems for determination of a wide variety of pesticide residues (Dehghan et al., 2010).

\subsubsection{Extract concentration and dilution to volume}

Great care must be exercised when extracts are evaporated to dryness, as trace quantities of many analytes can be lost in this way. A small volume of high boiling point solvent may be used as a 'keeper' and the evaporation temperature should be as low as practicable. Frothing and vigorous boiling of extracts, or dispersion of droplets, must be avoided. A stream of dry nitrogen or vacuum centrifugal evaporation is generally preferable to the use of an air stream for small-scale evaporation, as air is more likely to lead to oxidation or to introduce water and other contaminants.

Where extracts are diluted to a fixed volume, accurately calibrated vessels of not less than 1 $\mathrm{ml}$ capacity should be used and further evaporation avoided.

Analyte stability in extracts should be investigated during method validation. Storage of extracts in a refrigerator or freezer will minimize degradation but potential losses at the higher temperatures of an auto-sampler rack should not be ignored (Pihlström et al., 2009).

\subsection{Confirmation of results}

Negative results (residues below the RL ${ }^{5}$ ) can be considered confirmed if the recovery and $\mathrm{LCL}^{6}$ measurement for the batch are acceptable. Negative results for represented analytes are supported only indirectly by the recovery and LCL data for representative analytes and must be interpreted with caution.

${ }^{4}$ Gas Chromatography

${ }^{5}$ reporting level

${ }^{6}$ Lowest calibrated level 
Confirmation of positive results (residues at or above the RL) for represented analytes (i.e. those with no concurrent calibration and recovery) should be supported by the appropriate concurrent calibration and recovery determinations. Confirmation is not mandatory for all positive results and must be decided by the laboratory on a case-by-case basis.

Suspected MRL7 exceeds or unusual residues must be identified. The use of a highly specific detection system, such as mass spectrometry, is recommended (Pihlström et al., 2009).

\subsubsection{Identification}

Selective detectors employed with GC or $\mathrm{LC}^{8}$ such as ECD 9 , FPD $10, \mathrm{NPD}^{11}$ and fluorescence, offer only limited specificity. Their use, even in combination with different polarity columns, does not provide unambiguous identification. These limitations may be acceptable for frequently found residues, especially if some results are also confirmed using a more specific detection technique. Such limitations in the degree of identification should be acknowledged when reporting the results.

The common identification and measurement systems are listed below:

\section{i. Chromatographic separation system (GC or LC such as ECD, FPD, NPD and fluorescence):}

Generally, chromatography is a method for physically separation of components of mixtures and substances, based on differences in distribution in mobile and solid phases. Separation is resulted from different tendency of components to solid phase. Gas chromatography and liquid chromatography are the most common methods for pesticide residues analysis. In Gas-Liquid Chromatography (GLC) method, identification and detection of pesticide residues via standard detectors (ECD, FPD, NPD and fluorescence)are confirmed followed by extraction with a suitable solvent, volatile derivation, injection of the volatile derivate to the GC instrument and gaseous mobile phase pass from the column. Hence, GC can be combined with mass spectrometry to achieve high quality chromatograms with no interferences caused by overlapping/unresolved peaks from co-extracted compounds (Shokrzadeh, 2007).

ii. Mass spectrometry (MS) coupled to chromatography (GC-MS and LC-MS):

Mass spectrometry technique in combination with chromatography is the most common and proper identification method, which has a high selectivity and specificity. Mass spectrometry coupled to GC can identify and measure the low residue level of insecticides and poisons (Shokrzadeh, 2007).

For GC-MS procedures, the chromatographic separation should be carried out using capillary columns. For LC-MS procedures, the chromatographic separation can be performed using any suitable LC column. In either case, the minimum acceptable retention time for the analyte(s) under examination should be at least twice the retention time corresponding to the void volume of the column. The retention time (or relative retention time) of the analyte in the sample extract must match that of the calibration standard (may need to be matrix matched) within a specified window after taking into consideration the

\footnotetext{
${ }^{7}$ maximum residue limits

${ }^{8}$ Liquid chromatography

${ }^{9}$ Electron Capture Detection

${ }^{10}$ Flame Photometric Detection

${ }^{11}$ Nitrogen-Phosphor Detection
} 
resolving power of the chromatographic system. The ratio of the chromatographic retention time of the analyte to that of a suitable internal standard, i.e. the relative retention time of the analyte, should correspond to that of the calibration solution with a tolerance of $\pm 0.5 \%$ for GC and $\pm 2.5 \%$ for LC (Pihlström et al., 2009).

iii. UV-spectrometry:

The residues of insecticides and pesticides can be analyzed by UV spectrometry system. The limiting factor for use of this analyzing system is its unspecificity for some insecticides (Shokrzadeh, 2007).

\subsection{Reporting of results}

\subsubsection{Expression of results}

Results should normally be expressed as the chemical name defined by the MRL and in $\mathrm{mg} / \mathrm{kg}$. Residues below the Reporting Limit should be reported as $<\mathrm{RL} \mathrm{mg} / \mathrm{kg}$.

\subsubsection{Calculation of results}

In general, residues data are not to be adjusted for recovery. If they are adjusted for recovery, then this must be stated. In this case they should be adjusted using the mean value from 3 recoveries performed in the same matrix, and analyzed in the same batch of samples. Where confirmed data are derived from a single test portion (i.e. the residue is not violative), the reported result should be that derived from the detection technique considered to be the most accurate. Where results are obtained by two or more equally accurate techniques, the mean value may be reported.

Where two or more test portions have been analyzed, the arithmetic mean of the most accurate results obtained from each portion should be reported. Where good comminuting and/or mixing of samples have been undertaken, the RSD of results between test portions should not exceed $30 \%$ for residues significantly above the LOQ ${ }^{12}$. Close to the LOQ, the variation may be higher and additional caution is required in deciding whether or not a limit has been exceeded (Pihlström et al., 2009).

\subsubsection{Rounding of data}

It is essential to maintain uniformity in reporting results. In general, results $\geq 0.01$ and $<10$ $\mathrm{mg} / \mathrm{kg}$ should be rounded to two significant figures; results $\geq 10 \mathrm{mg} / \mathrm{kg}$ may be rounded to three significant figures or to a whole number. Reporting limits should be rounded to 1 significant figure at $<10 \mathrm{mg} / \mathrm{kg}$ and two significant figures at $\geq 10 \mathrm{mg} / \mathrm{kg}$. These requirements do not necessarily reflect the uncertainty associated with the data. Additional significant figures may be recorded for the purpose of statistical analysis. In some cases the rounding may be specified by, or agreed with the customer/stakeholder of the monitoring (Pihlström et al., 2009).

\subsubsection{Qualifying results with uncertainty data}

To this end, laboratories should have available sufficient data derived from method validation/verification, inter-laboratory studies (e.g. proficiency tests) and in-house quality control tests, which are applied to estimate the uncertainties.

${ }^{12}$ Limit of quantization 
Measurement uncertainty is a quantitative indicator of the confidence in the analytical data and describes the range around a reported or experimental result within which the true value can be expected to lie within a defined probability (confidence level). Uncertainty ranges must take into consideration all sources of error (Pihlström et al., 2009).

\section{Reduction}

Pesticide residues in or on plants may be unavoidable even when pesticides are used in accordance with Good Agricultural Practice (Uysal-Pala \& Bilisli, 2006; Processing studies (Appendix E), 1997). Further while remarkable progress has been made in the development of effective pesticides, the fact remains that a very small fraction of all applied pesticides is directly involved in the pesticidal mechanism. This implies that most of the applied pesticides find their way as 'residue' in the environment into the terrestrial and aquatic food chains where they undergo concentration and exert potential, long term, adverse health effects (Winteringham, 1971).

Pesticide residues are influenced by processing or household preparation stages such as washing, peeling and cooking etc. (Dikshit et al., 2003; Petersen et al., 1996). Processing studies allow a better estimate of the consumer exposure to the residues (Uysal-Pala, \& Bilisli, 2006). Studies into effects of storage and some commercial processing techniques on residues in food are a part of the registration requirements for pesticides in many countries. Reviewing the extensive literature showed that in most cases these steps lead to large reductions in residue levels in the prepared food, particularly through, washing, and peeling, fermentation, refrigeration and some other operations. The behaviour of residues in storage and processing can be rationalized in terms of the physico-chemical properties of the pesticide and the nature of the process. Recommendations are provided for the conduct of storage or processing studies on fate of pesticide residues in food so that data obtained is relevant, comparable and may be extrapolated to other situations (Holland et al., 1994).

Food processing techniques implies the set of methods and techniques used to transform raw ingredients into food or to transform food into other forms for consumption by humans or animals either in the home or by the food processing industry. The most common food processing techniques can aid in pesticide reduction. The techniques are described:

\subsection{Baking}

Baking is the technique of prolonged cooking of food by dry heat normally in an oven. It is primarily used for the preparation of bread, cakes, pastries and pies, tarts, and quiches. It is also used for the preparation of baked potatoes; baked apples; baked beans. For instance, commercially produced bread is an important component of every day diet in many countries. During bread making process, flour is subjected to biological (fermentation) and physical (baking) transformation (Sharma et al., 2005).

\subsection{Dairy product manufacture}

Milk and milk products form a main constituent of the daily diet. Butter, cheese and yoghurt are the popular dairy products (Abou-Arab, 1999). Hence it is important to study the effect of milk products manufacture on the concentration of pesticides and their metabolites.

\subsection{Drying}

Drying is the oldest method of preserving food. As compared with other methods, drying is quite simple. Food can be dried in several ways, for example, by the sun or in an oven or a 
food dryer can also be used. Drying has been found to reduce the pesticide residues considerably (Kaushik et al., 2009).

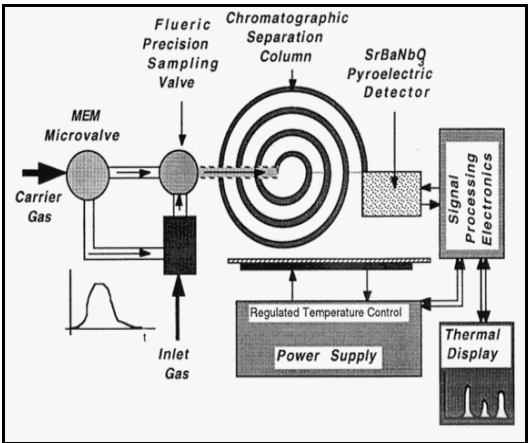

$\mathrm{a}_{1}$

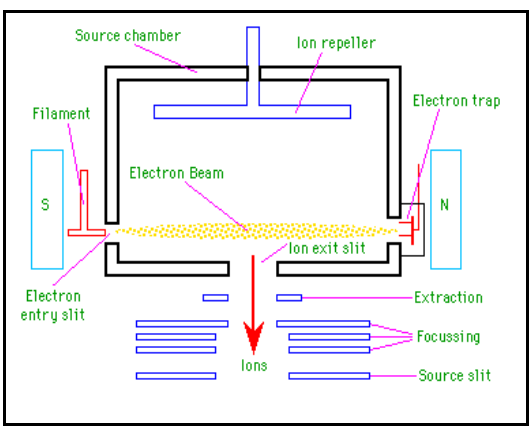

$\mathrm{b}_{1}$

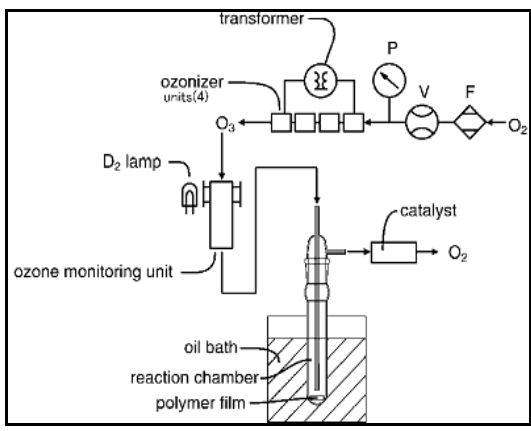

$\mathrm{C}_{1}$

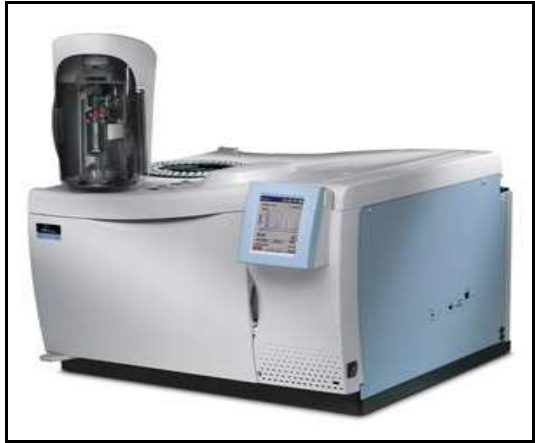

$\mathrm{a}_{2}$

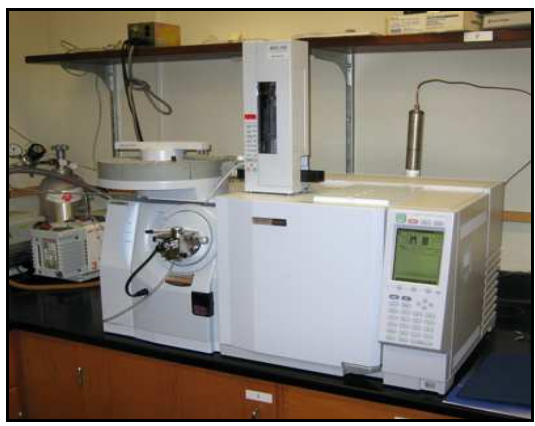

$\mathrm{b}_{2}$

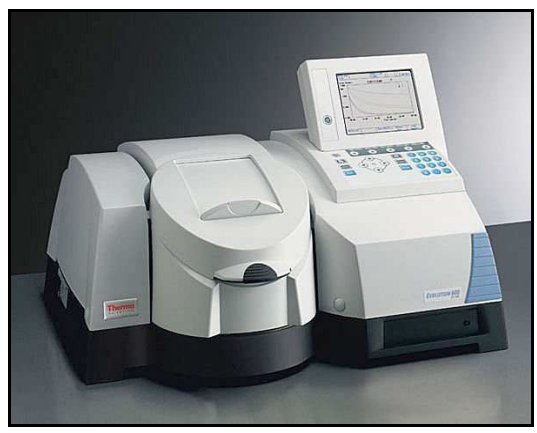

$\mathrm{C}_{2}$

Fig. 1. The Gas chromatography (GC), Gas chromatography-Mass spectroscopy (GC-MS), UV-spectroscopy schematics and instruments: $\left(a_{1}\right)$ GC components, $\left(a_{2}\right)$ GC instrument, $\left(b_{1}\right)$ GC-MS components, $\left(b_{2}\right)$ GC-MS instrument, $\left(c_{1}\right)$ UV-spectroscopy components, $\left(c_{2}\right)$ UVspectroscopy instrument. 


\subsection{Fermentation}

Fermentation is a simple process during which the enzymes hydrolyze most of the proteins to amino acids and low molecular weight peptides; starch is partially converted to simple sugars which are fermented primarily to lactic acid, alcohol and carbon dioxide (PardezLopez et al., 1991). Fermentation has been studied for reduction in pesticide residues.

In a fermentation method, the vegetables and fruits (e.g. cucumbers) are fermented in experimental, closed-top and dark fibreglass tanks. The surface halophilic and acid-tolerant bacteria (i.e. Lactobacillus plantarum) and fungi were as starter to establish lactic acid fermentation.

In a study, Fermentation of cucumbers lead to significantly lower amount of benomyl and mancozeb, compared with nonshrub cucumbers (Shokrzadeh \& Saeedi Saravi, 2008).

\subsection{Freezing and refrigeration}

Freezing food is a common method of food preservation which slows both food decay and most chemical reactions (Kaushik et al., 2009). In refrigeration method, the samples which were subjected to cold storage procedure were kept at $+4{ }^{\circ} \mathrm{C}$ in the refrigerator in polyethylene bags and darkly condition.

In a study it was found that when cucumbers contaminated at level of $2 \mathrm{~L} / 1000 \mathrm{~L}$ in water were refrigerated the reduction of residues were $5.3 \%, 22.4 \%, 43.7 \%, 52 \%$ and $68.2 \%$ after 2 , 4, 6, 8 and 10 days with diazinon and $14.7 \%, 28.2 \%, 49.1 \%, 63 \%$ and $74.7 \%$ loss after these specific days with malathion, respectively (Dehghan et al., 2010).

\subsection{Infusion}

Tea and coffee are popular beverages throughout the world. A cup of tea that cheers can also be an important route of human exposure to pesticide residues. It is therefore important to evaluate the percent transfer of pesticide residue from dried (made) tea to tea infusion, as tea is subjected to an infusion process prior to human consumption (Jaggi et al., 2000).

In addition, this procedure can be occurred to reduce the heavy metal residues in agricultural products. For example, despite of a high level of heavy metals, such as lead and Cadmium in dried tea leaves, the possibility of the entry of these metals into the tea infusion was minimal. There was an excessive amount of lead and Cadmium in all dried leaf samples, but these levels were not found in the tea infusions, as the time of infusion was less than 1 hour, which was not sufficient to release metals from leaves (Shokrzadeh et al., 2008).

\subsection{Juicing}

Commercial juicing operations generally use whole fruit. The residue levels in juices from fruit will depend on the partitioning properties of the pesticide between the fruit skins/pulp and the juice. The pulp or pomace by-products, which often include the skin, retain a substantial proportion of lipophilic residues. Thus, moderately to highly lipophilic pesticides such as parathion, folpet, captan and synthetic pyrethroids are poorly transferred into juices and the residues are further reduced by clarification operation, such as centrifugation or filtering (Holland et al., 1994).

\subsection{Malting}

Malting is a process applied to cereal grains; it is a combination of two processes, notably germination and the kiln-drying process. The fate of pesticides was determined from barley 
to malt. The amount remaining after malting ranged from $13-51 \%$ for fenitrothion and nuarimol. The stages of malting steeping, germination and kilning contributed to loss of pesticide residues (Navarro et al., 2007).

\subsection{Milling}

The milling of grains substantially removes the pesticide residues. Most residues are present in the outer portions of the grain, and consequently levels in bran are consistently higher than in wheat. Even for the pesticides which can enter the grain by translocation, residues are higher in the bran than in the flour (Holland et al., 1994).

\subsection{Peeling}

Peeling is an important step in the processing of most fruits and vegetables. Chemical peeling (mostly lye peeling), mechanical peeling (mainly abrasion peeling), steam peeling and freeze peeling are conventional methods for peeling in the processing of fruits and vegetables (Toker \& Bayindirli, 2003). A majority of the insecticides or fungicides applied directly to crops undergo very limited movement or penetration of the cuticle. It therefore follows that residues of these materials are confined to the outer surfaces where they are amenable to removal in peeling, operation. Peeling fresh fruits such avocado, bananas, citrus, cucumber, kiwifruit, mango and pineapple achieves virtually complete removal of residues from the fruit. For instance, removal of the skin, by peeling, leaves cucumber tissue below the waxy layer, therefore resulting in reduction of diazinon and malathion residues by more than $45.9 \%$ and $60.6 \%$ (Dehghan et al., 2010).

\subsection{Storage}

Grains are frequently stored long term (3-36 months) at ambient temperatures in bulk silos where insecticides may be applied post-harvest to reduce losses from storage pests (Holland et al., 1994; Joint Meeting on Pesticide Residues (JMPR), 1981). Grain based foods therefore have the potential to be a major source of residues in the diet for these insecticides. Studies on grain following post-harvest treatments with insecticides have generally shown that residues only decline rather slowly (Holland et al., 1994; Snelson, 1987). Residues of the more lipophilic materials tend to remain on the seed coat although a proportion can migrate through to the bran and germ which contain high levels of triglyceride (Anderegg \& Madisen, 1983; Holland et al., 1994).

For example, a post-harvest interval (storage for 10 days) reduced diazinon in cucumbers by $94.7 \%$. Overall disappearances of $97.8 \%$ of initial dose of malathion from cucumbers respectively were obtained (Dehghan et al., 2010).

\subsection{Thermal processing (canning, cooking)}

Application of heat to food commodities is commonly done through ordinary cooking, pressure cooking, microwave cooking, frying, sterilization and canning.

The commercial canning process in its various forms combines elements of washing, peeling, juicing, cooking and concentration.

Cooking is the act of preparing food for eating by the application of heat. It encompasses a vast range of methods depending on the customs and traditions, availability and the affordability of the resources. Literature is replete with work on effect of cooking on pesticide residues dissipation. 


\subsection{Washing}

Washing is the most common form of processing which is a preliminary step in both household and commercial preparation. Loosely held residues of several pesticides are removed with reasonable efficiency by varied types of washing processes (Street, 1969). The effects of washing depend on location of the residue in cucumbers, water solubility of the pesticide, temperature and type of wash. Polar, water soluble pesticides are more readily removed than low polarity materials (Kaushik, et al., 2006; Elkins, 1989). The Samples were washed following two washing procedures, soaking and dipping in water (at temperature 25-30 ${ }^{\circ} \mathrm{C}$ for 10 minutes) and detergent-washing.

For example, washing of cucumbers by dipping in water for 10 minutes reduced diazinon and malathion residues to $81.8 \%$ and $65.6 \%$ of initial concentration. Also, $34.6 \%$ and $44.2 \%$ loss in residues obtained with detergent-washing. Thus, washing with detergent was more effective to reduce the pesticides residue than water-washing. The investigation indicated that washing with water and or detergent solutions were necessary to decrease the intake of pesticide residues (Dehghan et al., 2010).

\subsection{Wine making}

During the manufacture of wine in addition to the transfer of residues from the grapes into the must, stability of residues to the fermentation and fining processes are important factors. Fermentation on the skins as carried out in red wine production is likely to lead to higher residues in raw wine. Residues in must may be absorbed to the solids produced during fermentation and thus be lost in the fining processes. However, a range of pesticides with suitable solubility and stability can give rise to residues in wine (Holland et al., 1994). This process usually is less used in some Muslim societies and countries; because wine consumption is banned for Muslims, based on the religious principles and costumes.

\section{Prevention}

In assessing dietary exposure to the chronic toxicological effects of pesticides, most regulatory authorities consider some measure of typical food intake, such as mean or median food consumption values. But for compounds that might be acutely toxic, it is important to know if the dietary intake over a relatively short period of time (such as a day) is safe. By examining exposure at such an extreme, acute assessment protects the safety of people who ingest more pesticide residues than virtually anyone else in the population.

The risk from pesticide residues is evaluated on the basis of two toxicological limit values: the ADI and the ARfD. ADI stands for 'Acceptable Daily Intake'. It indicates the amount of a substance which can be ingested daily over a lifetime by consumers without any appreciable health risk. The ADI is used to assess the chronic risk and the Acute Reference Dose (ARfD) to assess the acute risk. The ARfD is a comparatively new risk assessment tool. It is defined as the amount of a substance which a consumer can ingest from one meal or several meals spread over the day without any appreciable health risk (Whitford et al., 2006).

The chapter emphasizes the fact that the advantages associated with the application of pesticides in enhancing the agricultural productivity must be weighed against the possible health hazard arising from the toxic pesticide residues in food. First and foremost the application of pesticides should be in compliance with good agricultural practices, using 
only the required amounts. Further the current shift in world opinion from 'chemical farming' towards 'organic farming' is a sustainable approach to minimize the damage posed by widespread contamination of environment by pesticides. However, the challenge lies in achieving food safety in developing countries where the indiscriminate application of pesticides results in the presence of residues in food commodities. However, due to several socio-cultural and technical reasons, diffusion and acceptance of this approach among the farming community in developing countries like India has been very slow. Hence, it becomes urgent and important in the transient phase that some pragmatic solution should be developed. So in the transitory phase it is important to address the concern of food safety through suitable processing techniques and appropriate storage period that enhance food safety even in developing countries especially for the poor populace which cannot afford the expensive organic food. In this background common and simple processing techniques acquire significance for reducing the harmful pesticide residues in food. The effects of processing pesticide residues in food is an area where available information should be consolidated and missing information needs to be obtained through further research.

The following suggestions are presented for safety improvement along with daily progress of industries and industrial pollution:

- Initial focus on dietary risks and food chain;

- Determination of hazard effects of pesticides on human and animal health;

- Determination of standard limit values, such as ADI and ARfD;

- Frequent measurement of pesticide residues in agricultural products;

- Attention shifts to occupational risks;

- Public scrutiny over residential risks;

- Early federal laws (landscape and grounds management policy, pesticide reduction strategies);

- $\quad$ Study requirements and scientific education (to farmers, industries, etc.);

- Determination of testing guidelines;

- Establishment of reference laboratory equipped with analytical apparatuses, such as GC, GC-MS, HPLC13, etc;

- Optimization the food processing techniques (with regard to pesticide residue dissipation and nutrient content);

- Informing people about the reductive effects of house holding procedures (i.e. storage, washing, peeling, fermentation) on pesticide residues in agricultural products;

- Use of biological pest controls (such as pheromones and microbial pesticides), genetic engineering, and methods of interfering with insect breeding, as safer alternatives to chemical pesticides.

Overall, the chapter concerns to determine pesticide residue levels in agricultural products and compare it with standard limit values. The safety assessments can manifest the status of pesticide contamination in agricultural products, which is affected by water, soil and air pollution, and lead to apply prevention methods supported by governments (Shokrzadeh et al., 2009).

${ }^{13}$ high performance liquid chromatography 


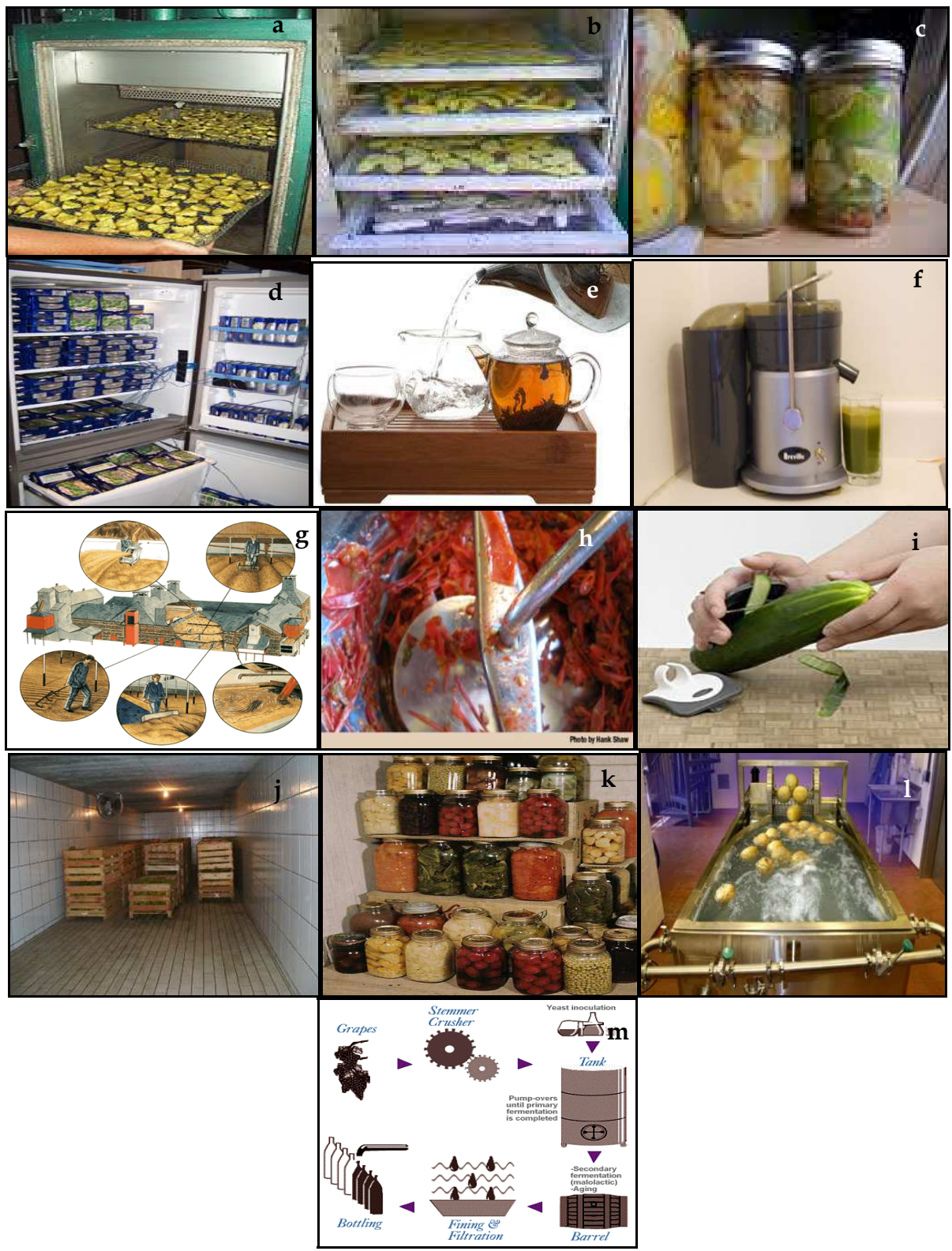

Fig. 2. Different processes for reduction of pesticide residues in agricultural products: (a) baking, (b) drying, (c) fermentation, (d) freezing, (e) infusion, (f) juicing, (g) malting, (h) milling, (i) peeling, (j) storage, (k) canning, (l) washing, $(\mathrm{m})$ wine making. 


\section{References}

Abou-Arab, A.A.K. (2002). Degradation of organochlorine pesticides by meat starter in liquid media and fermented sausage. Food and Chemistry Toxicology 40: 33-41.

Anderegg, B.M. \& Madisen, L.G. (1983). Journal of Economic Entomology 76: 733-736.

Dehghan, A., Ghorbani, M., Maghsoudlou, Y., Saeedi Saravi, S.S., Babaee, Z.A., Shokrzadeh, M. (2010). Effects of Washing, Peeling, Storage and Fermentation on Residue Contents of Malathion and Diazinon in Cucumbers Grown in Greenhouses. Food Chemistry, submitted.

Dikshit, A.K., Pachaurý, D.C. \& Jindal, T. (2003). Maximum residue limits and risk assessment of betacyfluthrin and imidacloprid on tomato. Bulletin of Environment and Contamination Toxicology 70: 1143-1150.

Elkins, E.R. (1989). Effect of commercial processing on pesticide residues in selected fruits and vegetables. Journal of the Association of Official Agricultural Chemists 72(3): 533535.

Food and Agriculture Organization of the United Nations (2002). International Code of Conduct on the Distribution and Use of Pesticides, 2007.

Hackenberg, D. (2007). Letter from David Hackenberg to American growers from March 14, 2007. Plattform Imkerinnen-Austria.

URL: WWW.imkerinnen.at.

Haefeker, W. (2000). Betrayed and sold out-German bee monitoring.

URL: WWW.beekeeping.com.

Holland, P.T., Hamilton, D., Ohlin, B. \& Skidmore, M.W. (1994). Effects of storage and processing on pesticide residues in plant products. IUPAC Reports on Pesticides (31). Pure and Applied Chemistry 66(2): 335-356.

Jaggi, S., Sood, C., Kumar, V., Ravindranath, S.D. \& Shanker, A. (2000). Loss of quinalphos during tea processing. Pestology 24(12): 42-46.

Joint Meeting on Pesticide Residues (JMPR) (1981). Monographs of toxicological evaluations monograph 011. Delta.

Kamrin, M.A. (1997). Pesticide Profiles: toxicity, environmental impact, and fate. CRC Press.

Kaushik, G., Satya, S., Naik, S.N. (2009). Food processing a tool to pesticide residue dissipation-A review. Food Research International 42: 26-40.

Jeyaratnam, J. (1990). Acute pesticide poisoning: a major global health problem. World Health Stat $Q 43$ (3): 139-144.

McCauley, L.A., Anger, W.K., Keifer, M., Langley, R., Robson, M.G. \& Rohlman, D. (2006). Studying health outcomes in farm worker populations exposed to pesticides. Environmental Health Perspectives 114 (3): 953-960.

Miller, G.T. (2004), Sustaining the Earth, 6th ed. Thompson Learning, Inc. Pacific Grove, California.

Navarro, S., Perez, G., Navarro, G. \& Vela, N. (2007). Decline of pesticide residues from barley to malt. Food Additives and Contaminants 24(8): 851-859.

Palmer, W.E., Bromley, P.T. \& Brandenburg, R.L. (2007). Wildlife \& pesticides-Peanuts. North Carolina Cooperative Extension Service. 
Pardez-Lopez, O., Gonzales-Casteneda, J. \& Carabenz-Trejo, A. J. (1991). Influence of solid substrate fermentation on the chemical composition. Journal of Fermentation and Bioengineering 71: 58-62.

Petersen, B., Tomerlin, J.R. \& Barraj, L. (1996). Pesticide degradation: Exceptions to the Rule. Food Technology 50(5): 221-223.

Pihlström, T., et al. (2009). Method validation and quality control procedures for pesticide residues analysis in food and feed.

Processing studies (Appendix E) (1997). Commission of the European Communities, Directorate General for Agriculture, 7035/VI/95rev.5.

Rell M.J., Galvin J.R. (2008). Safe Application Of Pesticides And Herbicides. Connecticut Department of Public Health.

URL: WWW.ct.gov/dph.

Rockets, R. (2007). Down On The Farm? Yields, Nutrients And Soil Quality. URL: WWW.Scienceagogo.com.

Sharma, J., Satya, S., Kumar, V. \& Tewary, D.K. (2005). Dissipation of pesticides during bread making. Journal of Chemical Health and Food Safety, 17-22.

Shokrzadeh, M., Saeedi Saravi, S.S. \& Zehtab Yazdi, Y. (2009). Lindane residues in cultivated cucumber and in the most consumed fish in Caspian Sea (Iran). Toxicology and Industrial Health 25(8): 517-523.

Shokrzadeh, M. \& Saeedi Saravi, S.S. (2008). Measurement of residues of benomyl and mancozeb pesticides in shrub and nonshrub cucumbers sampled from different regions of Mazandaran province (Iran). Toxicological and Environmental Chemistry 91(4): 627-630.

Shokrzadeh, M., Saberyan, M. \& Saeedi Saravi, S.S. (2008). Assessment of lead (Pb) and cadmium $(\mathrm{Cd})$ in 10 samples of Iranian and foreign consumed tea leaves and dissolved beverages. Toxicological and Environmental Chemistry 90(5): 879-883.

Shokrzadeh, M. (2007). Veterinary toxicology. Institute of Scientific and Practical University, Jahad Keshavarzi Publication.

Snelson, J.T. (1987). Grain protectants. ACIAR monograph series (Australia) (Vol. 3, pp. 448 p). Australian Centre for International Agricultural Research, Canberra, Australia.

Street, J.C. (1969). Methods of removal of pesticide residues. Canadian Medical Association Journal 100: 154-160.

Toker, I. \& Bayindirli, A. (2003). Enzymatic peeling of apricots, nectarines and peaches. Lebensmittel-Wissenschaftund-Technologie 36(2): 215-221.

Uysal-Pala, C. \& Bilisi, A. (2006). Fate of endosulfan and deltamethrin residues during tomato paste production. Journal of Central European Agriculture 7(2): 343-348.

Wells, M. (2007). Vanishing bees threaten U.S. crops.

URL: WWW.bbc.co.uk.

Whitford, F., Kronenberg, J., Lunchick, C., Driver, J., Tomerlin, R., Wolt, J., et al. (2006). Pesticides and Human Health Risk Assessment, Purdue Pesticide Program, Purdue University Cooperative Extension Service. 
Winteringham, F.P.W. (1971). Some global aspects of pesticide residue problems, Israel Journal of Entomology 6(2): 171-181.

Zeissloff, E. (2001). Schadet imidacloprid den bienen (in German).

URL: WWW.beekeeping.com. 


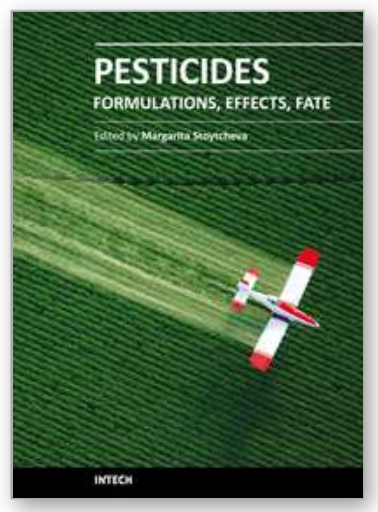

\author{
Pesticides - Formulations, Effects, Fate \\ Edited by Prof. Margarita Stoytcheva
}

ISBN 978-953-307-532-7

Hard cover, 808 pages

Publisher InTech

Published online 21, January, 2011

Published in print edition January, 2011

This book provides an overview on a large variety of pesticide-related topics, organized in three sections. The first part is dedicated to the "safer" pesticides derived from natural materials, the design and the optimization of pesticides formulations, and the techniques for pesticides application. The second part is intended to demonstrate the agricultural products, environmental and biota pesticides contamination and the impacts of the pesticides presence on the ecosystems. The third part presents current investigations of the naturally occurring pesticides degradation phenomena, the environmental effects of the break down products, and different approaches to pesticides residues treatment. Written by leading experts in their respective areas, the book is highly recommended to the professionals, interested in pesticides issues.

\title{
How to reference
}

In order to correctly reference this scholarly work, feel free to copy and paste the following:

Mohammad Shokrzadeh and Seyed Soheil Saeedi Saravi (2011). Pesticides in Agricultural Products: Analysis, Reduction, Prevention, Pesticides - Formulations, Effects, Fate, Prof. Margarita Stoytcheva (Ed.), ISBN: 978953-307-532-7, InTech, Available from: http://www.intechopen.com/books/pesticides-formulations-effectsfate/pesticides-in-agricultural-products-analysis-reduction-prevention

\section{INTECH}

open science | open minds

\section{InTech Europe}

University Campus STeP Ri

Slavka Krautzeka 83/A

51000 Rijeka, Croatia

Phone: +385 (51) 770447

Fax: +385 (51) 686166

www.intechopen.com

\section{InTech China}

Unit 405, Office Block, Hotel Equatorial Shanghai

No.65, Yan An Road (West), Shanghai, 200040, China

中国上海市延安西路65号上海国际贵都大饭店办公楼 405 单元

Phone: +86-21-62489820

Fax: $+86-21-62489821$ 
(C) 2011 The Author(s). Licensee IntechOpen. This chapter is distributed under the terms of the Creative Commons Attribution-NonCommercialShareAlike-3.0 License, which permits use, distribution and reproduction for non-commercial purposes, provided the original is properly cited and derivative works building on this content are distributed under the same license. 